\title{
The emergence of pandemic influenza viruses
}

\author{
Yi Guan (ه), Dhanasekaran Vijaykrishna, Justin Bahl, Huachen Zhu, Jia Wang, Gavin J. D. Smith \\ State Key Laboratory of Emerging Infectious Diseases, Li Ka Shing Faculty of Medicine, The University of \\ Hong Kong, Hong Kong SAR, China \\ $\varangle$ Correspondence: yguan@hkucc.hku.hk \\ Received October 27, 2009; accepted November 7, 2009
}

\begin{abstract}
Pandemic influenza has posed an increasing threat to public health worldwide in the last decade. In the 20th century, three human pandemic influenza outbreaks occurred in 1918, 1957 and 1968, causing significant mortality. A number of hypotheses have been proposed for the emergence and development of pandemic viruses, including direct introduction into humans from an avian origin and reassortment between avian and previously circulating human viruses, either directly in humans or via an intermediate mammalian host. However, the evolutionary history of the pandemic viruses has been controversial, largely due to the lack of background genetic information and rigorous phylogenetic analyses. The pandemic that emerged in early April 2009 in North America provides a unique opportunity to investigate its emergence and development both in human and animal aspects. Recent genetic analyses of data accumulated through long-term influenza surveillance provided insights into the emergence of this novel pandemic virus. In this review, we summarise the recent literature that describes the evolutionary pathway of the pandemic viruses. We also discuss the implications of these findings on the early detection and control of future pandemics.
\end{abstract}

KEYWORDS pandemic influenza, influenza virus, pandemics control

\section{INTRODUCTION}

In the twentieth century, three influenza viruses emerged in humans to cause major pandemics: the 1918 Spanish flu virus (H1N1), the 1957 Asian flu virus (H2N2), and the 1968
Hong Kong flu virus (H3N2). The 1918 Spanish influenza virus killed an estimated 20 to 50 million people worldwide, while the 1957 and 1968 viruses are estimated to have claimed from 500,000 to $2,000,000$ human lives. These pandemics were initiated by the introduction and successful adaptation of a novel haemagglutinin subtype to humans from an animal source, resulting in antigenic shift. The most striking characteristic of these pandemics is a shift in mortality towards younger age groups ( $<60$ years old) (Andreasen et al., 2008). It has also been noted that the increased mortality associated with these pandemics was observed in multiple waves over the course of 2 to 5 years from the time of their emergence (Miller et al., 2009). These pandemic viruses become established in humans as the cause of seasonal flu for many years until being replaced by a new pandemic virus. In this review, we focus on recent literature that describes the origins and evolutionary pathways of the three major pandemics of the 20th century and their implications on the future spread of the ongoing $\mathrm{A} / \mathrm{H} 1 \mathrm{~N} 1 / 2009$ pandemic.

\section{SPANISH FLU}

The origins and animal source of the genes of the 1918 Spanish influenza pandemic virus have been highly controversial. Before the genome of the 1918 pandemic virus was decoded, it has been widely considered that this infamous virus was likely derived from a direct avian origin (Gammelin et al., 1990; Gorman et al., 1990, 1991; Webster et al., 1992). With the availability of the genetic information on 1918 pandemic strain, represented by the full genome of $A / B r e v i g$ Mission/1/1918, phylogenetic analyses of all gene segments showed that the $1918 \mathrm{H} 1 \mathrm{~N} 1$ pandemic virus was most closely related to mammalian lineages, either with seasonal human H1N1 or classic swine H1N1 viruses. However, comparison of the consensus amino acid sequences suggested that the 
1918 pandemic strain carried more avian-like signatures than mammalian ones (Tumpey et al., 2005). Contrary to phylogenetic evidence, it has been extensively argued that the virus was derived directly from an avian progenitor (Taubenberger et al., 2005, 2006; Taubenberger and Morens, 2006).

Dating pandemic influenza viruses using Bayesian relaxed clock methods provided interesting insights into the emergence of the 1918 virus. Based on these analyses, Smith et al. (2009a) show that the 1918 virus was generated by reassortment between introduced avian viruses and previously circulating swine and human strains over a period of years rather than resulted from adaptation of an entire avian virus directly introduced into humans shortly before the pandemic. Furthermore, these results suggest that its PB2, NP and NS genes may have circulated in humans since the 1889 H3 influenza pandemic.

It was previously assumed that the seasonal $\mathrm{H} 1 \mathrm{~N} 1$ viruses were derived from the 1918 Spanish flu viruses. However, phylogenies show that only the PB1, PA, NP and N1 genes of seasonal $\mathrm{H} 1 \mathrm{~N} 1$ viruses were derived from the 1918 pandemic virus. Similarly, only PB2, M and NS genes of classic swine H1N1 were derived from the 1918 pandemic virus (Fig. 1). Thus, seasonal human $\mathrm{H} 1 \mathrm{~N} 1$ and classic swine $\mathrm{H} 1 \mathrm{~N} 1$ viruses were all reassortants partially derived from the 1918 pandemic strain. Three lineages of $\mathrm{H} 1 \mathrm{~N} 1$ variants might be co-circulating at a certain period of time (Fig. 1) (Smith et al., 2009a).

\section{ASIAN FLU AND 1968 HONG KONG FLU}

The 1957 and 1968 pandemics are characterized by incorporation of PB1 and novel surface protein genes (HA and/or NA) into the original constellation of gene segments that have been circulating in humans (Fang et al., 1981; Kawaoka et al., 1989; Masurel and Marine, 1973; Scholtissek et al., 1978). Phylogenetic studies show that the H2N2 virus that emerged in 1957 (H2N2/1957) was a genetic reassortant between previously circulating human $\mathrm{H} 1 \mathrm{~N} 1$ virus and avian viruses, with the novel $\mathrm{H} 2, \mathrm{~N} 2$ and PB1 genes derived from Eurasian avian sources (Fig. 1) (Kilbourne, 2006). Bayesian time of most recent common ancestor (TMRCA) estimates of the introduced genes of the $\mathrm{H} 2 \mathrm{~N} 2$ pandemic suggest that the introduction of these 3 genes into human populations occurred 2 to 6 years before the pandemic (Smith et al., 2009a). Date estimates of the H3 and PB1 segments from the $\mathrm{H} 3 \mathrm{~N} 2 / 1968$ pandemic strains indicate that the gene introduction occurred between 1966 and 1968. Notably, these H2N2 and $\mathrm{H} 3 \mathrm{~N} 2$ viruses were also revealed to have been cocirculated in humans for approximately 1 to 3 years prior to pandemic emergence.

Differences in the TMRCA estimates raised the possibility that the introduced genes of the H2N2 and H3N2 pandemic strains may have been introduced subsequently from multiple sources over a number of years. Because of a lack of sequence data for swine influenza during these periods, the involvement of pigs in the generation of these pandemic strains was elusive and cannot be precluded.

\section{A/H1N1/2009}

In March and early April 2009, a novel H1N1 virus lineage (A/ $\mathrm{H} 1 \mathrm{~N} 1 / 2009)$ previously undetected in humans emerged in Mexico and the United States (CDC, 2009), which was antigenically highly divergent from the seasonal $\mathrm{H} 1 \mathrm{~N} 1$, and to which the human population was mostly immunologically naïve. Shortly after its emergence, this virus has swept across the world, developing into the first influenza pandemic of the 21st century.

Advances in sequencing technologies and global sharing of sequence data enabled the rapid analyses and elucidation of the evolutionary pathway of this novel pandemic virus, which showed that each of its genomic segment fell within well-established swine influenza lineages that have been circulating in swine for more than 10 years prior to the current outbreak (Smith et al., 2009b). The majority of the genes of the $2009 \mathrm{~A} / \mathrm{H} 1 \mathrm{~N} 1$ viruses were derived from $\mathrm{H} 3 \mathrm{~N} 2$ and/or $\mathrm{H} 1 \mathrm{~N} 2$ triple reassortant viruses that were first found in pigs in North America in 1998 (Zhou et al., 1999), while their neuraminidase (N1) and matrix (M) genes were closely related to an $\mathrm{H} 1 \mathrm{~N} 1$ avian-like swine virus (Eurasian avianlike swine virus) that was initially found in pigs in Europe in 1979.

The Eurasian avian-like swine $\mathrm{H} 1 \mathrm{~N} 1$ viruses are entirely derived from the Eurasian avian gene pool (Ludwig et al., 1995). These viruses have reassorted with other circulating swine viruses and H3N2 human viruses in Europe and Asia (Schultz et al., 1991; Peiris et al., 2001). In particular, the avian-like H1N1 virus underwent reassortment with humanorigin H3N2 virus in mid-1980's and resulted in the generation of a European double reassortant $\mathrm{H} 3 \mathrm{~N} 2$ virus in pigs (with human origin of HA and NA genes, and avian origin for the remaining internal genes) (Schultz et al., 1991). Genetic and epidemiological findings revealed that the European reassortant H3N2 had been introduced into pig population in China during mid-1990's (Peiris et al., 2001), while the American triple reassortant viruses were also transmitted into pig populations in Asian countries in 2000's (Smith et al., 2009b). An H1N2 influenza virus isolated from pigs in Hong Kong in 2004 showed that only its NA gene was different from the 2009 pandemic virus, highlighting the possibility that the pandemic strain might have been generated years before its emergence in humans. It is interesting to note that, while the viruses circulating in North America have been introduced to Eurasia, Eurasian "avian-like" swine viruses have not been reported from swine in North America till date.

Even though genetic relationships of the novel pandemic virus remain relatively distant from those viruses identified 


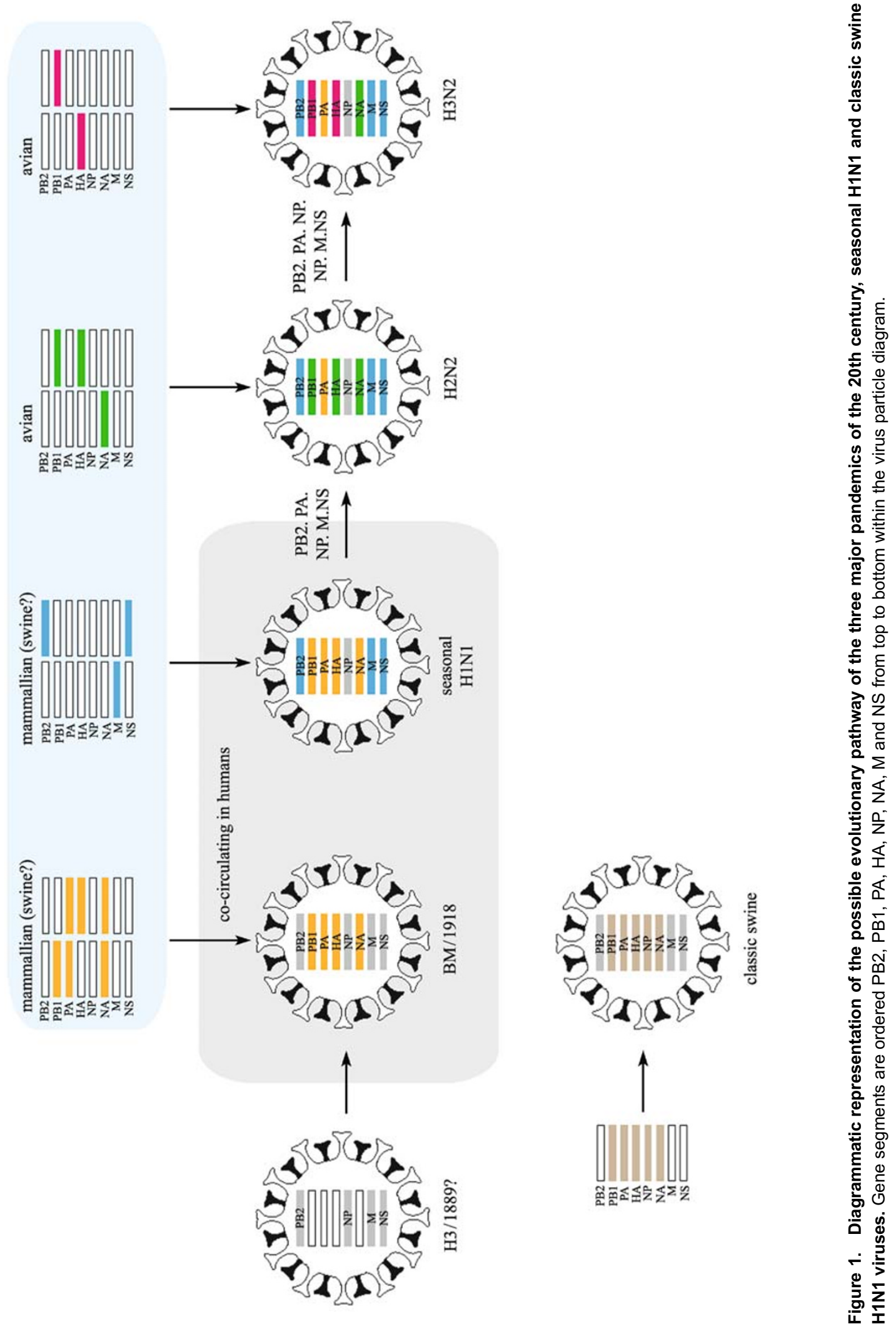


from pig population, it is clear that all the genetic components of this new virus have descended from influenza viruses known to have naturally occurred in swine populations (Fig. 2). These results provided the first direct evidence that pigs could independently facilitate the generation and emergence of pandemic influenza virus even without the involvement of human influenza virus.
Right now three major influenza A virus lineages are cocirculating in humans, including the seasonal $\mathrm{H} 1 \mathrm{~N} 1, \mathrm{H} 3 \mathrm{~N} 2$ and the pandemic $\mathrm{H} 1 \mathrm{~N} 1$ viruses. It is still unknown which lineage(s) will be replaced or become predominant in the future. However, it is not whether but when the viruses from different lineages will undergo further reassortment to generate new variants. A more serious scenario is whether

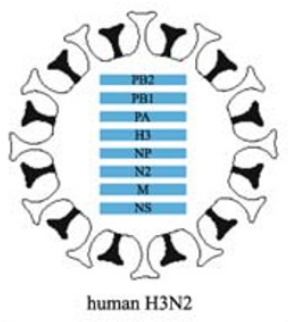

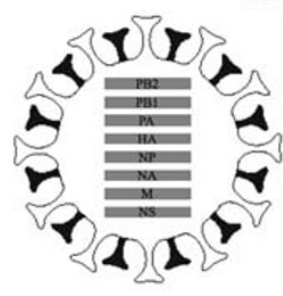

North American avian (gene pool)

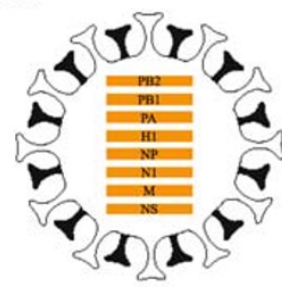

HIN1 classic swine
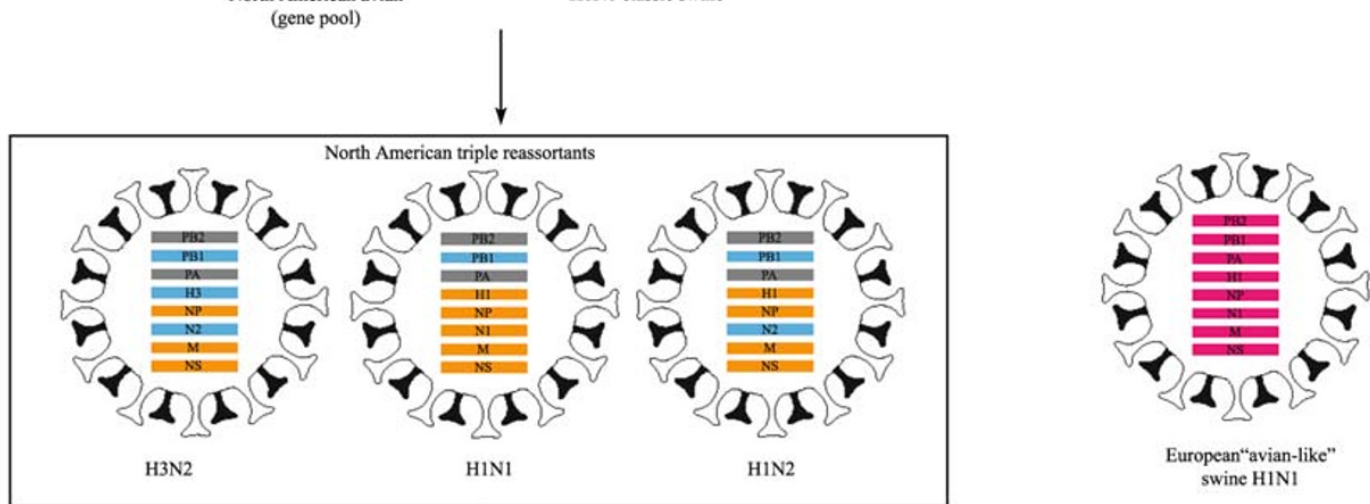

A/H1N1/2009
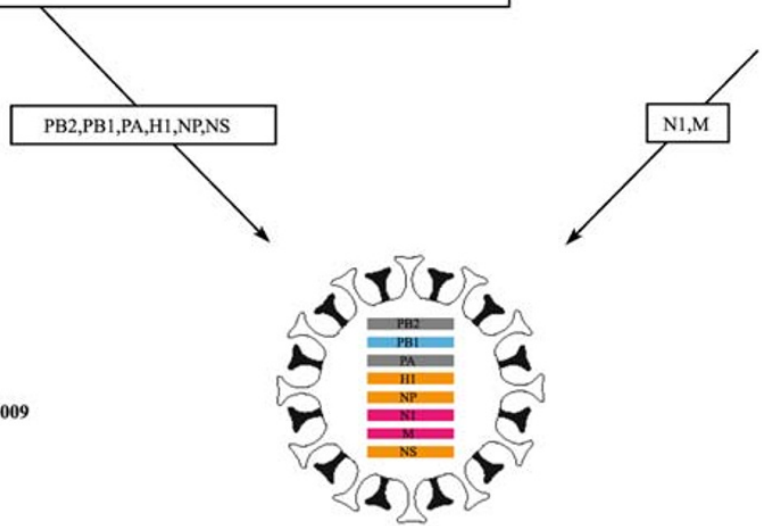

A/California/07/2009-like

Figure 2. Diagrammatic representation of the evolutionary history of $A / H 1 N 1 / 2009$ virus. Gene segments are ordered the same as Fig. 1. Arrows represent reassortment pathway of genotype development. Triple reassortant viruses (boxed) were first detected in swine from North America in 1998. Eurasian "avian-like" viruses were first detected in swine from Europe in 1979. 
the novel pandemic $\mathrm{H} 1 \mathrm{~N} 1$ virus would interact with those avian influenza viruses currently endemic in poultry to generate fatal strains with human-to-human transmissibility.

\section{CONCLUSIONS}

All pandemic influenza viruses of the 20th century derived from or emerged with a close genetic relationship to the 1918like viruses, while the current pandemic has an independent evolutionary pathway derived entirely from viruses circulating in mammals. The H2N2 and H3N2 pandemic viruses were descendants with further reassortment of the seasonal H1N1 and avian viruses. For these subtypes, swine represents a major host and was considered to play a key role in facilitating the reassortment events. The ongoing pandemic influenza virus was completely and independently generated through multiple reassortment events amongst viruses that are longterm perpetuated within pigs. Moreover, avian viruses with pandemic potential (e.g. H5N1 and H9N2 subtypes) have also been repeatedly detected in swine. This has naturally increased the likelihood of further reassortment between avian and human viruses and provided a new direction for the development of current influenza pandemic. These findings have highlighted the necessity for systematic surveillance of influenza in pigs that will provide early evidence for mixing of new genetic elements and the emergence of viruses with pandemic potential in humans.

\section{ACKNOWLEDGEMENTS}

This study was supported by Li Ka Shing Foundation, the Area of Excellence Scheme of the University Grants Committee of the Hong Kong Special Administrative Region Government (grant AoE/M-12/ 06), and the National Institutes of Health (NIH, National Institute of Allergy and Infectious Diseases contract HSN266200700005C).

\section{REFERENCES}

Andreasen, V., Viboud, C., and Simonsen, L. (2008). Epidemiologic characterization of the 1918 influenza pandemic summer wave in Copenhagen: implications for pandemic control strategies. J Infect Dis 197, 270-278.

Centers for Disease Control and Prevention (2009). Swine influenza A (H1N1) infection in two children-southern California, March-April 2009. Morb Mortal Wkly Rep 58, 400-402.

Fang, R., Jou, W.M., Huylebroeck, D., Devos, R., and Fiers, W. (1981). Complete structure of A/duck/Ukraine/63 influenza hemagglutinin gene: animal virus as progenitor of human $\mathrm{H} 3$ Hong Kong 1968 influenza hemagglutinin. Cell 25, 315-323.

Gammelin, M., Altmuller, A., Reinhardt, U., Mandler, J., Harley, V.R., Hudson, P.J., Fitch, W.M., and Scholtissek, C. (1990). Phylogenetic analysis of nucleoproteins suggests that human influenza $A$ viruses emerged from a 19th-century avian ancestor. Mol Biol Evol 7, 194-200.

Gorman, O.T., Donis, R.O., Kawaoka, Y., and Webster, R.G. (1990). Evolution of influenza A virus PB2 genes: implications for evolution of the ribonucleoprotein complex and origin of human influenza $A$ virus. J Virol 64, 4893-4902.

Gorman, O.T., Bean, W.J., Kawaoka, Y., Donatelli, I., Guo, Y.J., and Webster, R.G. (1991). Evolution of influenza A virus nucleoprotein genes: implications for the origins of H1N1 human and classical swine viruses. J Virol 65, 3704-3714.

Kawaoka, Y., Krauss, S., and Webster, R.G. (1989). Avian-to-human transmission of the PB1 gene of influenza A viruses in the 1957 and 1968 pandemics. J Virol 63, 4603-4608.

Kilbourne, E.D. (2006). Influenza pandemics of the 20th century. Emerg Infect Dis 12, 9-14.

Ludwig S., Stitz L., Planz O., Van H., Fitch W.M., and Scholtissek C. (1995) European swine virus as a possible source for the next pandemic? Virology 212, 555-561.

Masurel, N., and Marine, W.M. (1973). Recycling of Asian and Hong Kong Influenza A virus hemagglutinins in man. Am J Epidemiol 97, 44-49.

Miller, M.A., Viboud, C., Balinska, M., and Simonsen, L. (2009). The signature features of influenza pandemics-implications for policy. N Engl J Med 360, 2595-2598.

Peiris J.S., Guan, Y., Markwell, D., Ghose, P., Webster, R.G., and Shortridge, K.F. (2001). Cocirculation of avian H9N2 and contemporary "human" H3N2 influenza A viruses in pigs in southeastern China: potential for genetic reassortment? J Virol 75, 9679-9686.

Scholtissek, C., Rohde, W., von Hoyningen, V., and Rott, R. (1978). On the origin of the human influenza virus subtype H2N2 and H3N2. Virology 87, 13-20.

Schultz, U., Fitch, W.M., Ludwig, S., Mandler, J., and Scholtissek, C. (1991). Evolution of pig influenza viruses. Virology 183, 61-73

Smith, G.J., Bahl, J., Vijaykrishna, D., Zhang, J., Poon, L.L., Chen, H., Webster, R.G., Peiris, J.S., and Guan, Y. (2009a). Dating the emergence of pandemic influenza viruses. Proc Natl Acad Sci U S A 106, 11709-11712.

Smith, G.J., Vijaykrishna, D., Bahl, J., Lycett, S.J., Worobey, M., Pybus, O.G., Ma, S.K., Cheung, C.L., Raghwani, J., Bhatt, S., et al. (2009b). Origins and evolutionary genomics of the 2009 swine-origin H1N1 influenza A epidemic. Nature 459, $1122-1125$

Taubenberger, J.K., Reid, A.H., Lourens, R.M., Wang, R., Jin, G., and Fanning, T.G. (2005). Characterization of the 1918 influenza virus polymerase genes. Nature 437, 889-893.

Taubenberger, J.K., Reid, A.H., Lourens, R.M., Wang, R., Jin, G., and Fanning, T.G. (2006). Molecular virology: was the 1918 pandemic caused by a bird flu? (Reply). Nature 440, E9-10.

Taubenberger, J.K., and Morens, D.M. (2006). 1918 influenza: the mother of all pandemics. Emerg Infect Dis 12, 15-22.

Tumpey, T.M., Basler, C.F., Aguilar, P.V., Zeng, H., Solórzano, A., Swayne, D.E., Cox, N.J., Katz, J.M., Taubenberger, J.K., Palese, P., et al. (2005). Characterization of the reconstructed 1918 Spanish influenza pandemic virus. Science 310, 77-80.

Webster, R.G., Bean, W.J., Gorman, O.T., Chambers, T.M., and Kawaoka, Y. (1992). Evolution and ecology of influenza A viruses. Microbiol Rev 56, 152-179.

Zhou, N.N., Senne, D.A., Landgraf, J.S., Swenson, S.L., Erickson, G., Rossow, K., Liu, L., Yoon, K., Krauss, S., and Webster, R.G. (1999). Genetic reassortment of avian, swine, and human influenza A viruses in American pigs. J Virol 73, 8851-8856. 